\title{
A união entre o longform e o jornalismo literário
}

Alessandra de Falco ${ }^{1}$

\section{Introdução}

ESTE RELATO REÚNE FRAGMENTOS QUE CONFLUEM PARA REPRESENTAR O JORNALISMO LITERÁRIO NA WEB, EM longform. Por que não utilizar de recursos literários para representar a realidade em uma longa reportagem para a web? Empreendimentos recentes podem ser acompanhados nos projetos ARTE!Brasileiros ${ }^{2}$, The Intercept Brasil ${ }^{3}$ e Gama ${ }^{4}$, além dos espaços ofertados ao jornalismo literário na Agência Pública ${ }^{5}$, por exemplo. Destacando a revista piauí ${ }^{6}$, que desde 2006 , aproxima o Jornalismo da Literatura.

O jornalismo literário ganhou espaço na web através do longform e por trás do texto longo e das revelações das múltiplas fontes de informação está o trabalho árduo e incansável de um jornalista, sua investida de tempo e dedicação. Na riqueza em detalhes observadas em trabalhos como os exemplos a seguir, revela-se um complexo processo de rastros da criação e até dos criadores. São observadas as reportagens considerando-as resultados de e ainda em processos criativos, com o objetivo de compreender as características das produções, revelando um sistema de similaridades entre as obras, mas também de criações surpreendentes.

Tomando o jornalismo literário na web, em longform, como índice de processo de criação além de registro da memória da criação do autor jornalista e suas fontes, olhar para categorias como: recursos narrativos; observação participante; construção textual e visual de personagens; vinculação afetiva entre autor, fenômeno e público; atuação social e criação de pertencimento identitário; e uso de dados; possibilita agregar um maior conhecimento sobre esse percurso.

\section{Metodologia}

Para exemplificar o resultado da união entre o Jornalismo Literário e o longform optou-se por uma observação inicial a partir da Semântica Discursiva - inclusa na Semiótica - com o objetivo de olhar para o corpus de reportagens de cunho literário e “[...] investigar sua dimensão semântica e relacioná-lo à estratégia narrativa do narrador e do meio que utiliza” (MOTTA, 2013, p. 12) ${ }^{7}$. Optou-se por escolher como categorias semânticas - que são a base para a construção das reportagens - as características do Jornalismo Literário, observando a presença do narrador-autor em sua própria obra e considerando o formato longform disponível na web.

Considerando ainda os procedimentos sugeridos por Barros (2005, p. 12) ${ }^{8}$, de que "Para explicar 'o que texto diz' e 'como diz', a semiótica trata, assim, de examinar os procedimentos da organização textual e, ao mesmo tempo, os mecanismos

\footnotetext{
${ }^{1}$ Docente de Jornalismo da Universidade Federal de São João del-Rei (UFSJ) em exercício provisório na Escola de Comunicação da Universidade Federal do Rio de Janeiro (ECO-UFRJ). Membro da Rede JorTec (Rede de Pesquisa Jornalismo e Tecnologias Digitais). Contato: alessandra.falco@eco.ufrj.br.

${ }^{2}$ Disponível em: <https://artebrasileiros.com.br/>. Acesso em: 05 abr. 2021.

${ }^{3}$ Disponível em: <https://theintercept.com/brasil/>. Acesso em: 05 abr. 2021.

${ }^{4}$ Disponível em: <https://gamarevista.com.br/>. Acesso em: 05 abr. 2021.

${ }^{5}$ Disponível em: <https://apublica.org/>. Acesso em: 05 abr. 2021.

${ }^{6}$ Disponível em: <https://piaui.folha.uol.com.br/>. Acesso em: 05 abr. 2021.

${ }^{7}$ MotтA, Luiz Gonzaga. Análise crítica da narrativa. Brasília: Ed. UnB, 2013, p. 12.

${ }^{8}$ Barros, Diana Luz Pessoa de. Teoria semiótica do texto. São Paulo: Ática, 2005, p. 12.
} 
enunciativos de produção [...]”, foram observadas as características pelas quais o Jornalismo Literário se apresenta no longform como categorias / sub tópicos deste relato, sendo observadas de forma exploratória e experimental.

As seis reportagens estudadas durante a disciplina Redação Jornalística II, oferecida na Escola de Comunicação da Universidade Federal do Rio de Janeiro em 2020, foram divulgadas entre março de 2019 e abril de 2021 no website da piaú. O relato aborda o que caracteriza as narrativas literárias para, na sequência exemplificar, a partir da observação de reportagens, características do Jornalismo Literário encontradas nos longforms como: recursos narrativos, observação participante; construção textual e visual de personagens; vinculação afetiva entre autor, fenômeno e público; e atuação social e criação de pertencimento identitário.

Considera-se ainda a contribuição que a Crítica Genética pode trazer, a posteriori, para a investigação mais aprofundada da relação entre Jornalismo Literário e longform, observando que:

Seu objeto: os manuscritos literários, tidos como portadores do traço de uma dinâmica, a do texto em criação. Seu método: o desnudamento do corpo e do processo da escrita, acompanhado da construção de uma série de hipóteses sobre as operações escriturais. Sua intenção: a literatura como um fazer, como atividade, como movimento ${ }^{9}$.

Neste sentido, é possível considerar o objeto: as reportagens analisadas a seguir, o método: a construção do longform a partir das características do Jornalismo Literário, escolhidas como categorias e subcapítulos. A intenção: mostrar os rastros do processo de criação do Jornalismo Literário na web. E ainda, acredita-se que, apesar de todas as reportagens analisadas já terem sido publicadas, elas continuam sendo textos memoráveis e que contém vestígios do processo de criação e, neste sentido, considera-se a afirmação de Salles $\left(2018\right.$, p. 35) ${ }^{10}$, de que:

Ao nos deparamos com o objeto de estudo da crítica genética, estamos, necessariamente, acompanhando uma série de acontecimentos interligados, que levam à construção da obra: estamos diante de um objeto móvel, um objeto de criação. Na relação entre esses registros e a obra entregue ao público encontramos um pensamento em processo.

Por ser um trabalho inicial, tanto de escolha metodológica como de levantamento de corpus, o foco deste artigo ainda é mais descritivo do que crítico-analítico. Por isso, em um trabalho futuro, serão abordados também outras referências teóricas que fazem sentido para esta pesquisa, desde o aprofundamento na Semiótica até a Análise do Discurso, assim como o olhar para o estudo do newsmaking - dos processos produtivos no Jornalismo, que englobam estratégias de redação, incluindo o uso de diferentes modalidades comunicativas, como textos e imagens, presentes em longforms. "Analisar o discurso é, portanto, determinar, ao menos em parte, as condições de produção do texto" (BARROS, 2005, p. 54) ${ }^{11}$.

\footnotetext{
${ }^{9}$ GRÉSSILON, Almuth. Elementos de Crítica Genética: ler os manuscritos modernos. Porto Alegre: Editora da UFRGS, 2007, p.19.

${ }^{10}$ SALLES, Cecilia Almeida. Crítica genética: Fundamentos de estudos genéticos sobre o processo de criação artística. São Paulo: EDUC, 2008, p. 35.

${ }^{11}$ Barros, Diana Luz Pessoa de. Teoria semiótica do texto. São Paulo: Ática, 2005, p. 54.
} 


\section{Longform: a nova onda do jornalismo literário}

Da literatura impressa ao jornalismo literário impresso, e ao seu formato transfigurado no meio digital em um longform, as facilidades e ferramentas possibilitadas pelos diferentes sistemas gerenciadores de conteúdo na web possibilitaram a expansão de um formato aclamado no espaço analógico e pensado como menosprezado no digital. As apropriações de uma linguagem cuja extensão de espaço era longa, mas finita em um livro, ganha nova materialidade com a Internet, mas a demanda de tempo devido ao seu tamanho ainda é questionada.

Com efeito, o texto longo se destaca não apenas pelo formato, mas também pela apuração, contextualização e aprofundamento. Textos com essa característica propõem uma leitura mais lenta e um leitor disposto a dedicar tempo para a mesma. [...] Se o texto longo é polêmico, sua antítese, a velocidade e o excesso de informação, têm preocupado profissionais e diversos autores. A principal questão, nesse sentido, é a conhecida história da dicotomia entre qualidade e quantidade ${ }^{12}$.

Longas histórias antes contadas em livros impressos ganharam (muito) espaço no meio digital. Sistemas gerenciadores de conteúdo, das próprias empresas midiáticas, ou de acesso e uso gratuito para usuários - como Wix, Wordpress, Medium, Shorthand entre outros - possibilitam hoje aos autores jornalistas ampliarem as possibilidades de criação textual e hipermidiática, unindo diferentes modalidades comunicativas para apresentar com riqueza de detalhes grandes reportagens jornalísticas com cunho literário, possibilidade para estudar "[...] o que o texto diz e como ele faz para dizer o que diz" (BARROS, 2005, p. 11) ${ }^{13}$.

O principal reforço ao jornalismo literário para a web vem com o storytelling que representa o desafio de ir além do factual, baseado na apuração mais rigorosa, na checagem, possibilitando a apresentação de assuntos da contemporaneidade a partir de uma perspectiva não apenas transdisciplinar, mas um ecossistema de produção colaborativa e compartilhada, garantida por avanços nas técnicas de produção e suportes tecnológicos, cuja característica de alcance de público foi remodelada.

Jacobson, Marino e Gutsche $(2015 \text {, p. } 8)^{14}$ definem o longform como a nova onda do Jornalismo Literário, considerando “[...] a interação multimídia e técnicas literárias para criar significado dentro da história [...] e o surgimento de uma alternativa para a norma hipertextual de contar histórias na web". Justificando a importância do Jornalismo Literário, Lima (2019, p. $\mathrm{XV}^{15}$ ) destaca que:

O mundo da narrativa do real resgata também o prazer da boa leitura, pois seus bons autores conduzem o leitor a uma viagem simbólica pelos temas, territórios, cenários reais, personagens, eventos, fatos, sentimentos, emoções, impressões, gostos, cores, ritmos e sons da vida tal qual é, em sua natureza orgânica verdadeira, complexa, cativante, às vezes aconchegante, às vezes ameaçadora. Nessa viagem, autor e leitor levam na bagagem a inteligência e os sentidos.

\footnotetext{
${ }^{12}$ LONGHI, Raquel Ritter; WINQUES, Kérler. O LUGAR DO LONGFORM NO JORNALISMO ONLINE: Qualidade versus quantidade e algumas considerações sobre o consumo. BRAZILIAN JOURNALISM RESEARCH - Volume 1 - Número 1 - 2015, p. 113.

${ }^{13}$ Barros, Diana Luz Pessoa de. Teoria semiótica do texto. São Paulo: Ática, 2005, p. 11.

${ }^{14}$ JACOBSON, Susan; MARINO, Jacqueline; GUTSCHE, Robert. The digital animation of literary journalism. Journalism (online). 2015, p. 8.

${ }^{15}$ LIMA, Edvaldo Pereira. Páginas ampliadas: o livro-reportagem como extensão do jornalismo e da literatura. Barueri-SP: Manole, 2009, p. XV.
} 
Dowling (2019) ${ }^{16}$ debruça-se sobre a narrativa longa para a web afirmando-a como o renascimento do jornalismo profundo e não enraizado em fins comerciais e políticos, permitindo cada vez mais a aproximação com a chamada independência do jornalista autor. Baccin $(2017)^{17}$ afirma a relação entre o jornalismo Literário e o longform a partir da análise de reportagens em suas dimensões (tamanho e tempo de produção e leitura), a partir do olhar para recursos técnicos (layout e design) e também elementos de qualidade (atreladas às características do webjornalismo, como hipertextualidade e multimidialidade).

Conceição $(2018)^{18}$ analisa como elementos multimídias são incorporados em produções jornalísticas de cunho literário publicadas no UOL TAB. Martinez $(2017)^{19}$ destaca a inclusão de recursos digitais, como, por exemplo, que proporcionam interação, que colaboram para a valorização do jornalismo narrativo - termo utilizado muitas vezes como sinônimo pelos pesquisadores do jornalismo literário. Segundo Barros $\left(2005\right.$, p. 22 ${ }^{20}$, “[...] os investimentos fazem do objeto um objeto-valor e é, assim, por meio do objeto que o sujeito tem acesso aos valores".

O encontro do jornalismo literário, prática originária da década de 60, nos EUA, que combina “[...] recursos literários com técnicas de investigação jornalística” (FARIA, 2011, p. 29) ${ }^{21}$, com o longform, se dá no marco do nascimento deste, que foi a publicação da reportagem veiculada pelo The New York Times, Snow Fall ${ }^{22}$, em 2012, utilizada desde então como um modelo por "Além de ter inovado na estrutura do fluxo narrativo e na integração das várias modalidades comunicativas [texto, áudio, vídeo etc] que compõem a história contada, a reportagem fez cair por terra a premissa de que os leitores não lêem [...] reportagens longas no ambiente digital" (BACCIN, 2017, p. 93) 23.

É impossível falar de jornalismo literário sem citar Edvaldo Pereira Lima $\left(1998^{24}, 2009^{25}, 2014^{26}\right)$ que desde 1951 se debruça sobre estudos sobre a relação entre jornalismo e literatura e o resultado dessa união: o livro-reportagem. Para além das aproximações das áreas editoriais e literárias, o autor demonstra como as fusões entre realidade e ficção podem permitir a criação de documentos memoráveis. Pena $(2006)^{27}$ é outra referência nacional, e para o ensino do jornalismo literário, uma vez que trabalha os subgêneros como a crítica, a biografia e a reportagem:

Afinal, o que é jornalismo literário? Não se trata apenas de fugir das amarras da redação ou de exercitar a veia literária em um livro-reportagem. O conceito é muito mais amplo. Significa

\footnotetext{
${ }^{16}$ DowLING, David O. Immersive Longform: Storytelling Media, Technology, Audience. London-UK: Routledge, 2019.

${ }^{17}$ BACCIN, Alciane. A narrativa longform em reportagens hipermídia. Estudos em Jornalismo e Mídia, Santa Catarina, v. 14, n. 1, 2017, p. 89-101. Disponível em: <https://periodicos.ufsc.br/index.php/jornalismo/article/view/1984-6924.2017v14n1p89/35056>. Acesso em: 06 mai. 2021.

${ }^{18}$ CONCEIÇÃo, Cintia Silva da. As Narrativas Multimídia no Jornalismo Literário: Análise do TAB. Intercom Sociedade Brasileira de Estudos Interdisciplinares da Comunicação. 41 Congresso Brasileiro de Ciências da Comunicação. Joinville-SC, 2 a 8/09/2018. Disponível em: <http://www.intercom.org.br/sis/eventos/2018/resumos/R13-0743-1.pdf> . Acesso em: 06 mai. 2021.

${ }^{19}$ MARTINEZ, Monica. JornalismoLiterário: revisão conceitual, história e novas perspectivas. Intercom, Rev. Bras. Ciênc. Comun., São Paulo, v. 40, n. 3, p. 21-36, dez. 2017. Disponível em: <http://www.scielo.br/scielo.php?script=sci_arttext\&pid=S1809_ 58442017000300021\&lng=en\&nrm=iso >. Acesso em: 06 mai. 2021.

${ }^{20}$ BArros, Diana Luz Pessoa de. Teoria semiótica do texto. São Paulo: Ática, 2005, p. 22.

${ }^{21}$ FARIA, Nídia Sofia. Jornalismo literário: um olhar histórico para o gênero e suas características. Comunicação Pública, Especial 01E - 2011, p. 29.

${ }^{22}$ Disponível em: <https://www.nytimes.com/projects/2012/snow-fall/index.html\#/?part=tunnel-creek>. Acesso em: 16 set. 2021.

${ }^{23}$ Op. cit.

${ }^{24}$ LIMA, Edvaldo Pereira. O que é livro-reportagem. São Paulo: Brasiliense, 1998.
}

25 ______. Páginas ampliadas: o livro-reportagem como extensão do jornalismo e da literatura. Barueri-SP: Manole, 2009.

26 _. Jornalismo Literário para Iniciantes. São Paulo: EDUSP, 2014.

${ }^{27}$ PENA, Felipe. Jornalismo Literário. São Paulo: Editora Contexto, 2006. 
potencializar os recursos do jornalismo, ultrapassar os limites dos acontecimentos cotidianos, proporcionar visões amplas da realidade, exercer plenamente a cidadania, romper as correntes burocráticas do lide, evitar os definidores primários e, principalmente, garantir perenidade e profundidade aos relatos. No dia seguinte, o texto deve servir para algo mais do que simplesmente embrulhar o peixe na feira ${ }^{28}$.

No jornalismo literário observa-se maior descrição e detalhamento de possibilidades enunciativas menos presas ao lide e à pirâmide invertida, ou seja, menos formatada nos padrões liberais de produção industrial da notícia. Enquanto que nas notícias factuais, o lide visa responder às seis perguntas: quem?, o quê?, quando?, onde?, como e por quê?, no lide cena - no passado denominado de nariz de cera pela crítica à prolixidade - a ideia é despertar a curiosidade, surpreender, sem necessariamente ir direto ao assunto, mas, de forma alguma, hoje, apenas floreando.

No primeiro, caso, presente em reportagens factuais, o seu sentido se justifica a partir da pirâmide invertida, técnica que indica a apresentação dos fatos principais no início, continuação das informações na sequência, com a possibilidade de corte ao final - uma vez que um ponto pode não ser tão importante e também pode não haver espaço para todo o conteúdo.

Já no lide cena, utilizado hoje por revistas como piaú e Gama, pode haver a construção de um cenário que não necessariamente engloba os principais fatos da história. E no caso da web, com a opção do formato em longform, a pirâmide é horizontal, uma vez que não é preciso cortar nada da ideia inicial e os conteúdo podem ser ramificados em hiperlinks. Portanto, no ambiente da web, o jornalismo literário pode driblar a primeira formatação apresentada, sem, contudo, abrir mão de apresentar todas as informações importantes para a história ao longo do texto, o que possibilita estudar sua estruturação "[...] que faz dele um todo de sentido" (BARROS, 2005, p. 11) ${ }^{29}$.

O jornalismo literário articula a estética narrativa com o real, produzindo narrações contemporâneas dentro de uma nova lógica de processos produtivos que, apesar de correr contra o tempo, ser voltada para o imediatismo, ainda assim tem espaço - necessário - para grandes obras como livros e reportagens de profundidade que vão à contramão do momento atual, quando estamos no auge da viralização das desinformações e do questionamento do papel informativo da imprensa. "O jornalismo literário é uma viagem de descoberta pelo território do real, por todos os mundos que constituem aquilo que achamos que é a realidade. [...] A literatura criativa de não ficção volta-se para a realidade, para compreendê-la” (LIMA, 2009, p. 436) ${ }^{30}$.

\section{Recursos narrativos: literatura no jornalismo longform}

Inicia-se a observação do corpus deste relato pela reportagem “A metástase” ${ }^{31}$ sobre o caso do assassinato Marielle Franco, a riqueza de detalhes, tão característica da literatura, é um instrumento utilizado repetidas vezes pelo repórter: "Foi aplaudida, abriu o sorriso grande que lhe era característico e levantou-se, ajeitando a saia com estampas florais e a blusa azul-marinho de alças finas" (ABREU, 2019, www) ${ }^{32}$.

\footnotetext{
${ }^{28}$ Ibidem.

${ }^{29}$ Barros, Diana Luz Pessoa de. Teoria semiótica do texto. São Paulo: Ática, 2005, p. 11.

${ }^{30}$ LIMA, Edvaldo Pereira. Páginas ampliadas: o livro-reportagem como extensão do jornalismo e da literatura. Barueri-SP: Manole, 2009, p. 436.

${ }^{31}$ ABreU, Allan de. A metástase. piaú, Edição 150, março 2019. Disponível em: <https://piaui.folha.uol.com.br/materia/ametastase >. Acesso em: 12 mai. 2020.

${ }^{32}$ Ibidem.
} 
Ele também narra o momento da cena do crime com análise balística - incluindo a descrição de onde as balas se alojaram -, como a morte aconteceu e por onde escorreu o sangue. As estratégias literárias, como a reconstrução detalhada de cenas, diálogos e personagens são amplamente exploradas:

Ferreira disse ainda ter ouvido os dois tramarem a morte de Marielle em um restaurante da Zona Oeste, em junho de 2017. 'Eu estava numa mesa, a uma distância de pouco mais de 1 metro dos dois. Eles estavam sentados numa mesa ao lado. O vereador falou alto: 'Tem que ver a situação da Marielle. A mulher está me atrapalhando'33.

São reconstituídos, de maneira pormenorizada, elementos que compõem o cenário (informações visuais, sonoras etc.), que provavelmente seriam deixadas de lado em uma reportagem mais concisa e que possui um gênero em que a informação se sobrepõe ao estilo textual. Já na reportagem "A mãe perfeita" ${ }^{34}$, o autor abusa das descrições de cenas para ambientar e geolocalizar a história.

A impressão de estar dentro da história é proporcionada, pois o público vai descobrindo as inconsistências da tragédia aos poucos, assim como os investigadores descobriram quando estavam cobrindo o caso. A reportagem convida a explorar o caminho percorrido pelo repórter e a tirar suas próprias conclusões da situação.

Conforme a história se passa, e os suspeitos aparecem, o autor tem o cuidado de apresentar as informações dosadas e sem spoiler sobre o fim, indo totalmente na contramão da pirâmide invertida, práxis da hard news. Ele aproveita para discorrer com informações sobre o que é filicídio e sobre como é incomum uma mãe matar o filho - o que traz à tona a dúvida sobre a culpa da mãe -, apesar de ela já ter confessado o crime.

\section{Observação participante}

A presença física dos repórteres no processo de construção da matéria, confirmam a observação participante, cuja origem científica está na Sociologia e refere-se à “[...] inserção do pesquisador no ambiente natural de ocorrência do fenômeno e de sua interação com a situação investigada" (PERUZZO, 2017, p. 162) ${ }^{35}$. Em “A última Coca-Cola do Capitólio”36, o recorte da reportagem foi feito através do olhar e da experiência de um jornalista que estava no local, dentro do prédio do Congresso dos Estados Unidos durante a invasão por centenas de manifestantes pró-Trump, no dia 6 de janeiro de 2021, dia da recontagem dos votos eleitorais que concedia a vitória ao oponente, o democrata Joe Biden.

A narrativa construída pelo jornalista transmite com detalhes os desafios da cobertura jornalística de grandes eventos como este. Ele se descreve como "homem-orquestra", pois fazia a cobertura sozinho, com um tripé e um celular, sem a ajuda de um cinegrafista. Precisou ser ágil, responder sob pressão e improvisar. A reportagem, em primeira pessoa, traz uma proximidade enunciativa como efeito de sentido. Fiorin $(2001)^{37}$ discute a instauração de pessoas, espaço e tempo nos discursos: a proximidade do "eu, aqui, agora" e o distanciamento do "ele, lá, no tempo de então".

\footnotetext{
${ }^{33}$ Ibidem.

${ }^{34}$ Melo, Itamar. A mãe perfeita. piauí, Edição 170, novembro 2020. Disponível em: <https://piaui.folha.uol.com.br/materia/a-mae-perfeita>. Acesso em: 12 mai. 2020.

${ }^{35}$ Peruzzo, Cicilia Maria Khroling. Pressupostos epistemológicos e metodológicos da pesquisa participativa: da observação participante à pesquisa-ação. Estudios sobre las culturas contemporáneas, v. XXIII, n. Especial III, 2017, p. 162.

${ }^{36}$ VÁsQuez, Cristóbal. A ÚlTiMA COCA-COLA DO CAPITÓLIO. piaú, Edição 173, fevereiro 2021. Disponível em: <https://piaui.folha.uol.com.br/materia/ultima-coca-cola-do-capitolio>. Acesso em: 20 mai. 2021.

${ }^{37}$ FIORIN, José Luiz. As astúcias da enunciação. São Paulo: Ática, 2001, p. 33.
} 
A característica de observação participante representa a proximidade real entre o jornalista e o acontecimento e demonstra que "Ao mergulhar no universo do processo criador, as camadas superpostas de uma mente em criação vão sendo lentamente reveladas e surpreendentemente compreendidas” (SALLES, 2008, p. 15) ${ }^{38}$, convergindo para as possíveis interpretações das obras de cunho literário.

\section{Construção textual e visual de personagens}

Ao longo da reportagem "A mãe perfeita" ${ }^{39}$, as personagens são construídas mais pelas características comportamentais do que pelas físicas. Por exemplo, sabe-se que a mãe, Dougokensky, tem mania de limpeza e de organização, tem apreço pelos itens pessoais - mesmo na prisão, ela pede que o filho guarde suas roupas - frieza após os atos de morte, é metódica e tem múltiplas personalidades. Esse exemplo demonstra o "[...] objetivo de se investigar os padrões de comportamento dos personagens de uma história, para se compreender suas motivações, seus valores, a origem possível de determinadas atitudes, a consequência de uma postura" (LIMA, 2009, p. 379) ${ }^{40}$.

[...] enquanto o jornalismo de pirâmide utiliza entrevistados como fontes de informação amparadas e validadas a partir das instituições de poder que representam, no jornalismo literário esses indivíduos se transformam em personagens que, retratados em seu sentir e agir no mundo, têm a validação de sua fala articulada a partir de suas vivências, que lhes conferiria credibilidade de modo independente de um amparo institucional ${ }^{41}$.

Em outro exemplo, a reportagem "A gente acolhe" ${ }^{42}$, o cuidado está na composição de todas as personagens, sendo um exemplo, a jornalista ter preferido não citar o nome das crianças vítimas, mas trazer outros elementos para ajudar na caracterização, como em: "Durante a preparação para o procedimento, ela contou aos plantonistas que adora jogar futebol, torce por times do Rio de Janeiro porque os capixabas são muito fracos e teve uma experiência legal como goleira de handebol da escola" (CRUZ, 2021, www) ${ }^{43}$.

\footnotetext{
38 SALLES, Cecilia Almeida. Crítica genética: Fundamentos de estudos genéticos sobre o processo de criação artística. São Paulo: EDUC, 2008, p. 15.

39 MElo, Itamar. A mãe perfeita. piaú, Edição 170, novembro 2020. Disponível em: <https://piaui.folha.uol.com.br/materia/a-mae-perfeita>. Acesso em: 12 mai. 2020.

${ }^{40}$ LiMA, Edvaldo Pereira. Páginas ampliadas: o livro-reportagem como extensão do jornalismo e da literatura. Barueri-SP: Manole, 2009, p. 379.

${ }^{41}$ PASSOS, Mateus Iuri. Jornalismo literário, humanização e polifonia: perfis da música erudita em piauí. Rev. Estud. Comun., Curitiba, v. 15, n. 36, jan./abr. 2014, p. $05 . \quad$ Disponível em: <https://periodicos.pucpr.br/index.php/estudosdecomunicacao/article/view/22453/21543>. Acesso em: 11 mai. 2021.

42 Cruz, Angélica Santa. “A gente acolhe”. piaú, edição 174, março 2021. Disponível em: <https://piaui.folha.uol.com.br/materia/a-gente-acolhe/\#>. Acesso em: 17 mai. 2021.

${ }^{43}$ Ibidem.
} 


\section{Vinculação afetiva entre autor, fenômeno e público}

É possível observar que, por exemplo, na reportagem "A metástase" ${ }^{44}$, ao introduzir as personagens, o autor sempre traz um breve perfil que fisga a atenção do leitor, apresentando cada um deles como em um romance policial. Esse tipo de abordagem cria vinculação afetiva:

Depois de viver uma década no Rio de Janeiro, o delegado Giniton Lages, 44 anos, praticamente perdeu o sotaque caipira. Paulista de Jaú, ele se formou em direito no interior de São Paulo. Seu sonho era ser promotor de Justiça. Durante cinco anos prestou concursos públicos para a carreira, sem sucesso. Decidiu então tentar uma vaga de delegado na Polícia Civil ${ }^{45}$.

O vínculo criado e aprofundado entre repórter, personagens e leitor a partir de depoimentos que não somente exemplificam como é lidar com transtornos mentais na pandemia, mas também criam empatia são observados também na

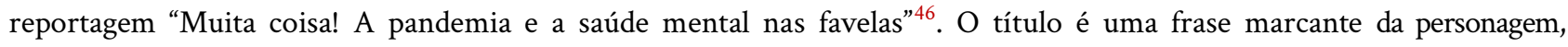
representando sua personalidade. Dados da Organização Mundial da Saúde contextualizam o leitor e tornam a situação mais próxima, mostrando que a Covid-19 não é somente um problema nacional, mas de escala global.

A narrativa, como instrumento de vinculação, é constituída tanto por linhas cognitivas quanto afetivas. A noção do afeto, aliás, parece ser um dos elementos centrais de qualquer narrativa: a possibilidade de criar um vínculo com o outro a partir de uma história compartilhada não deixa de ser, lembra Motta (2012), uma das formas de estabelecimento de uma relação (MARTINO, 2016, p. 46 $)^{47}$.

Em "A última Coca-Cola do Capitólio" ${ }^{48}$, o repórter descreve as experiências desafiadoras que viveu ao estar dentro da cena no momento da invasão. Quando revela a correria pela galeria do Congresso para conseguir sinal de celular para a entrada ao vivo, quando diz que estava "morrendo de fome" por estar horas sem comer e quando relata os ataques à imprensa pelos manifestantes, isso cria uma empatia no público, que talvez nunca tenha parado para pensar nos processos de construção das notícias que chegam até seu lar.

O espaço da narrativa, em suas vinculações sociais, também parece apontar para isso: o exercício de narrar algo implica também uma vivência afetiva com o mundo que se vai narrar. [...] $\mathrm{O}$ componente estético da narrativa não se desliga, nesse ponto, do componente afetivo propriamente dito; ao contrário, parece que seria possível situar o afeto no coração do elemento

\footnotetext{
${ }^{44}$ ABreU, Allan de. A metástase. piaú, Edição 150, março 2019. Disponível em: <https://piaui.folha.uol.com.br/materia/ametastase >. Acesso em: 12 mai. 2020.

45 Ibidem.

${ }^{46}$ Antenore, Armando. Muita coisa! A pandemia e a saúde mental nas favelas. piaú, Edição 168, setembro 2020. Disponível em: <https://piaui.folha.uol.com.br/materia/muita-coisa >. Acesso em: 20 mai. 2021.

${ }^{47}$ MARTINO, Luís Mauro Sá. De um eu ao outro: narrativa, identidade e comunicação com a alteridade. Parágrafo, v. 4, n. 1, fev. 2016, p. 46. Disponível em: <http://revistaseletronicas.fiamfaam.br/index.php/recicofi/article/view/377/376>. Acesso em: 26 mai. 2021.

${ }^{48}$ Op. cit.
} 
sensível. O vínculo estético, ligado ao afeto, é um dos modos fundamentais da comunicação, e sua presença na narrativa é fundamental para a criação de laços com o mundo narrado ${ }^{49}$.

Percebe-se em relação às reportagens literárias supracitadas que "O avesso de todas as coisas e a imensidão íntima das pequenas coisas são visitados. Transpostos os limites exteriores da obra, quão espaçoso é o interior” (SALLES, 2008, p. 18) ${ }^{50}$. Para melhor aprofundamento da categoria exposta, considera-se, em momento oportuno, o estudo da recepção das reportagens literárias, considerando o que diz Barros (2005, p. 61) $)^{51}$ sobre o “[...] contrato que se estabelece entre o enunciador e o enunciatário e nos meios empregados na persuasão e na interpretação".

\section{Atuação social e criação de pertencimento identitário}

Em "A última Coca-Cola do Capitólio" ${ }^{2}$, o jornalista utiliza seu texto para alertar o leitor quanto ao comportamento inadequado dos manifestantes, no que se refere às medidas de proteção contra a Covid-19: “A maioria das pessoas estava sem máscara. Não se importavam em desafiar a Covid [...] um eleitor [...], insistia que regras de distanciamento social para prevenir a Covid eram inúteis, e convidava os presentes a se abraçarem" (VÁSQUEZ, 2021, www) ${ }^{53}$. Em outro momento do texto, o autor faz questão de mencionar o uso da máscara por ele, no exercício da notícia: "De tanto eu falar, minha máscara caía a todo momento. Eu estava coberto de suor e com dor nas pernas, cansado por ficar tanto tempo em pé diante da câmera" (VÁSQUEZ, 2021, www) ${ }^{54}$.

Já na reportagem "A sobrevivente" ${ }^{55}$, a criação de pertencimento identitário se dá através, primeiramente, do tema. A violência contra as mulheres no Brasil, infelizmente, é um assunto recorrente. Trata-se de um universo particular e universal ao mesmo tempo. Detalhes e acontecimentos singulares, mas que fazem parte de uma realidade cotidiana para milhares de mulheres. Exemplo: marido que não a deixava usar batom vermelho, saia curta; a chama de oferecida por ter cumprimentado um ex-companheiro. De certa forma, a própria reportagem e os ricos detalhes dos abusos e agressões são uma forma de protesto.

Na reportagem "A gente acolhe" ${ }^{n 6}$, para além de noticiar um fato, a reportagem constrói uma sequência histórica que explica a situação do aborto no país e como ele vem sendo inviabilizado. O caráter de denúncia está presente ao longo de todo o texto, principalmente na parte em que a jornalista aborda como o poder público tenta esconder informações - como os hospitais públicos que realizam o procedimento - sobre o acesso ao aborto legal. Dessa forma é construída a reportagem literária longa e em formato também de apelo.

\footnotetext{
${ }^{49}$ Op. cit.

${ }^{50}$ SALLES, Cecilia Almeida. Crítica genética: Fundamentos de estudos genéticos sobre o processo de criação artística. São Paulo: EDUC, 2008, p. 18.

${ }^{51}$ BArros, Diana Luz Pessoa de. Teoria semiótica do texto. São Paulo: Ática, 2005, p. 61.

52 VÁsqueZ, Cristóbal. A ÚlTIMA COCA-COLA DO CAPITÓLIO. piaú, Edição 173, fevereiro 2021. Disponível em: <https://piaui.folha.uol.com.br/materia/ultima-coca-cola-do-capitolio >. Acesso em: 20 mai. 2021.

${ }^{53}$ Ibidem.

${ }^{54}$ Ibidem.

${ }^{55}$ BATISTA JR., João. A sobrevivente - Uma mulher luta para reconstruir seu rosto e sua vida. piaú, Edição 175, abril 2021. Disponível em: <https://piaui.folha.uol.com.br/materia/a-sobrevivente>. Acesso em: 26 mai. 2021.

${ }^{56}$ CRUZ, Angélica Santa. “A gente acolhe”. piaú, edição 174, março 2021. Disponível em:

https://piaui.folha.uol.com.br/materia/a-gente-acolhe/\#>. Acesso em: 17 mai. 2021.
} 


\section{considerações finais}

Enfim, observa-se que, por mais que existam similaridades nas reportagens de cunho literário, é possível encontrar criações surpreendentes. Como, por exemplo, cenários que convergem como uma oportunidade do jornalista imergir por mais tempo em determinada temática, se envolver com as histórias que estão sendo cobertas, quiçá fazer parte delas e assim, possibilitar a criação de uma narrativa na qual o público também possa imergir.

Ao buscar maior compreensão sobre os princípios que norteiam as reportagens jornalísticas literárias na web, foram destacadas e exemplificadas suas principais características: recursos narrativos; observação participante; construção textual e visual de personagens; vinculação afetiva entre autor, fenômeno e público; e atuação social e criação de pertencimento identitário.

Assim, é coerente afirmar que os recursos escolhidos pelos autores são responsáveis por criar apresentar, por meio do jornalismo literário em longform, bastidores de uma cobertura noticiosa que não seriam revelados em hardnews, são traçados a partir de maneira mais subjetiva de informar, o que concede ao leitor uma maneira de entender melhor sobre um problema, conhecendo mais a fundo a história de outras pessoas.

\section{Referências bibliográficas}

ABREU, Allan de. A metástase. piauí, Edição 150, março 2019. Disponível em: < https://piaui.folha.uol.com.br/materia/a-

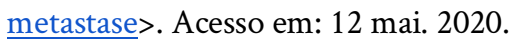

ANTENORE, Armando. Muita coisa! A pandemia e a saúde mental nas favelas. piauí, Edição 168, setembro 2020. Disponível em: <https://piaui.folha.uol.com.br/materia/muita-coisa $>$. Acesso em: 20 mai. 2021.

BACCIN, Alciane. A narrativa longform em reportagens hipermídia. Estudos em Jornalismo e Mídia, Santa Catarina, v. 14, n. 1, 2017, p. 89-101. Disponível em: <https://periodicos.ufsc.br/index.php/jornalismo/article/view/19846924.2017v14n1p89/35056>. Acesso em: 06 mai. 2021.

BARros, Diana Luz Pessoa de. Teoria semiótica do texto. São Paulo: Ática, 2005.

BATISTA JR., João. A sobrevivente - Uma mulher luta para reconstruir seu rosto e sua vida. piauí, Edição 175 , abril 2021. Disponível em: <https://piaui.folha.uol.com.br/materia/a-sobrevivente>. Acesso em: 26 mai. 2021.

CRUZ, Angélica Santa. “A gente acolhe”. piauí, edição 174, março 2021. Disponível em: <https://piaui.folha.uol.com.br/materia/a-gente-acolhe/\#>. Acesso em: 17 mai. 2021.

ConCEIÇÃo, Cintia Silva da. As Narrativas Multimídia no Jornalismo Literário: Análise do TAB. Intercom - Sociedade Brasileira de Estudos Interdisciplinares da Comunicação. 41 $^{\circ}$ Congresso Brasileiro de Ciências da Comunicação. JoinvilleSC, 2 a 8/09/2018. Disponível em: <http://www.intercom.org.br/sis/eventos/2018/resumos/R13-0743-1.pdf> . Acesso em: 06 mai. 2021.

DowLING, David O. Immersive Longform: Storytelling Media, Technology, Audience. London-UK: Routledge, 2019.

FARIA, Nídia Sofia. Jornalismo literário: um olhar histórico para o gênero e suas características. Comunicação Pública, Especial 01E - 2011, p. 29-44.

FIORIN, José Luiz. As astúcias da enunciação. São Paulo: Ática, 2001.

FLoRES, Lucas S.; Santos, Salete R. P. dos. Jornalismo Literário: um estudo de caso na contemporaneidade. CES REVISTA, Juiz de Fora, v. 32, n. 1, 2018, pp. 83-98. Disponível em: <https://seer.cesjf.br/index.php/cesRevista/article/view/1470>. Acesso em: 12 mai. 2021. 
GRÉSSILON, Almuth. Elementos de Crítica Genética: ler os manuscritos modernos. Porto Alegre: Editora da UFRGS, 2007.

JACOBSON, Susan; Marino, Jacqueline; Gutschejr, Robert. The digital animation of literary journalism. Journalism (online). 2015.

LiMA, Edvaldo Pereira. O que é livro-reportagem. São Paulo: Brasiliense, 1998.

Páginas ampliadas: o livro-reportagem como extensão do jornalismo e da literatura. Barueri-SP: Manole, 2009.

Jornalismo Literário para Iniciantes. São Paulo: EDUSP, 2014.

LONGHI, Raquel Ritter; Winques, Kérler. O lugar do longform no jornalismo online: Qualidade versus quantidade e algumas considerações sobre o consumo. Brazilian journalism research - Volume 1 - Número 1 - 2015.

MARTINEZ, Monica. Jornalismo Literário: revisão conceitual, história e novas perspectivas. Intercom, Rev. Bras. Ciênc. Comun., São Paulo, v. 40, n. 3, dez. 2017, pp. 21-36. Disponível em: <http://www.scielo.br/scielo.php?script=sci_arttext\&pid=S180958442017000300021\&lng=en\&nrm=iso>. Acesso em: 06 mai. 2021.

Martino, Luís Mauro Sá. De um eu ao outro: narrativa, identidade e comunicação com a alteridade. Parágrafo, v. 4, n. 1, fev. 2016, pp. 40-49. Disponível em: <http://revistaseletronicas.fiamfaam.br/index.php/recicofi/article/view/377/376>. Acesso em: 26 mai. 2021.

MElo, Itamar. A mãe perfeita. piauí, Edição 170, novembro 2020. Disponível em: <https://piaui.folha.uol.com.br/materia/a-mae-perfeita>. Acesso em: 12 mai. 2020.

PASSOS, Mateus Iuri. Jornalismo literário, humanização e polifonia: perfis da música erudita em piauí. Rev. Estud. Comun., Curitiba, v. 15, n. 36, jan./abr. 2014, pp. 64-78. Disponível em: <https://periodicos.pucpr.br/index.php/estudosdecomunicacao/article/view/22453/21543> . Acesso em: 11 mai. 2021.

De fontes a personagens: definidores do real no jornalismo literário. Intercom - Sociedade Brasileira de Estudos Interdisciplinares da Comunicação, 40 Congresso Brasileiro de Ciências da Comunicação, Curitiba-PR, 04 a 09/09/2017. Disponível em: <https://portalintercom.org.br/anais/nacional2017/resumos/R12-3009-1.pdf>. Acesso em: 10 mai. 2021.

PENA, Felipe. Jornalismo Literário. São Paulo: Editora Contexto, 2006.

O jornalismo Literário como gênero e conceito. Revista Contracampo, n. 17, 2007.

PERUZZO, Cicilia Maria Khroling. Pressupostos epistemológicos e metodológicos da pesquisa participativa: da observação participante à pesquisa-ação. Estudios sobre las culturas contemporáneas, v. XXIII, n. Especial III, 2017, pp.161-190.

SALLES, Cecilia Almeida. Crítica genética: Fundamentos de estudos genéticos sobre o processo de criação artística. São Paulo: EDUC, 2008.

VÁSQUeZ, Cristóbal. A ÚlTIMA COCA-COLA DO CAPITÓLIO. piauí, Edição 173, fevereiro 2021. Disponível em: <https://piaui.folha.uol.com.br/materia/ultima-coca-cola-do-capitolio >. Acesso em: 20 mai. 2021. 